\title{
What role might the social outcomes of education play during the COVID-19 lockdown?
}

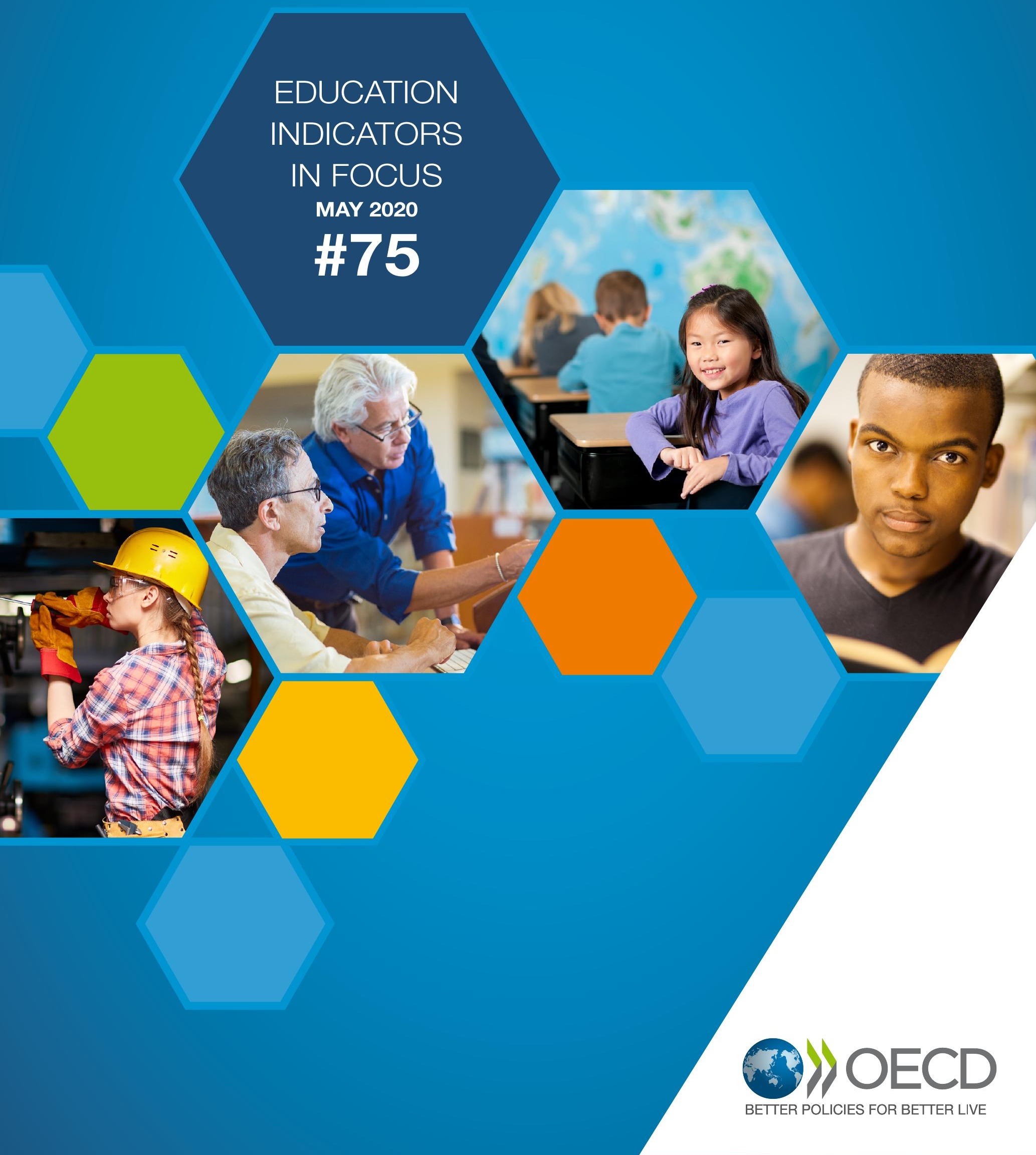


- Mental health is at stake during the confinement period, particularly for those who already suffered from anxiety or depression before the outbreak. Data collected before the outbreak show that the share of adults who reported suffering from depression decreases with educational attainment.

- Those with lower levels of education are more likely to suffer from domestic violence and exposure to it impairs the self-esteem and the educational attainment of children. The rise in domestic violence during the COVID-19 outbreak may therefore have important immediate and long-term impact.

- Healthy habits during confinement include maintaining social contacts with friends and family, a practice that has been shown to increase with educational attainment.

In late December 2019, an outbreak of a severe acute respiratory syndrome coronavirus (COVID-19) was developing in Wuhan (Hubei, China). Three months later, this local outbreak had developed into a world pandemic, severely damaging the economy, infecting millions of people and causing a significant death toll (Johns Hopkins University, 2020 ). While this was not the world's first pandemic, the world was not equipped to contain the spread of COVID-19. Since 2000, severe acute respiratory syndrome (SARS), swine flu, Middle East respiratory syndrome (MERS) and Ebola have tested global systems but they never paralysed the world's economy and affected our social interactions as COVID-19 is doing.

Countries and governments are under pressure to rapidly change their policies and adopt measures to protect their population and limit the negative health, economic and social impact of COVID-19 (OECD, 2020 ${ }_{[22}$ ). In many countries, governments have confined their populations to limit the spread of the virus. This means individuals also need to adjust to a new reality and find strategies to cope with confinement.

The positive outcomes from education could play an important role in helping people get through this crisis. As well as enjoying better economic situations, tertiary-educated adults are generally in better health (physical and mental) and have more social interactions than adults with lower levels of education. All these attributes could contribute to reducing the negative impact of the confinement period.

\section{Mental health is put to the test during the lockdown and data has shown that self-reported depression was higher among people with low educational attainment}

During the pandemic, listening to the news can increase stress and anxiety (WHO, 2020 ${ }_{[3]}$ ). People who have had mental health concerns such as depression may experience increased levels of distress during the outbreak (Centers for Disease Control and Prevention, $202 \mathrm{O}_{[4 \mid}$ ). The World Health Organization estimate that depression affects over 250 million people worldwide, making it the leading cause of disability (WHO, $\left.2020_{[5}\right)$. Given the already high prevalence of depression prior to the outbreak, and the increased stress associated with COVID-19, identifying those factors contributing to greater distress and those that can lower stress and anxiety will be important. Higher educational attainment and its associated social and labour market outcomes can help adults in this situation. For example, tertiary-educated adults tend to have higher incomes meaning they can afford larger living spaces and are less likely to be confined in cramped conditions. Lower educated people are generally more at risk of being unemployed, and the current economic situation may exacerbate this likelihood. This may in turn increase their likelihood of suffering from anxiety.

In most of the OECD countries that took part in the 2014 European Health Interview Survey (EHIS), adults with lower levels of educational attainment were more likely than tertiary-educated ones to report having suffered depression in the 12 months prior to the survey. On average across the 26 OECD countries participating in the $2014 \mathrm{EHIS}, 8 \%$ of 25-64 year-olds reported suffering from depression in the 12 months prior to the survey. Figure 1 shows that attaining upper secondary or post-secondary non-tertiary education is associated with better emotional well-being. This is particularly the case in Austria, Hungary, Iceland, Ireland, Norway, Portugal and Slovenia, where the difference in self-reported depression rates between adults with below upper secondary education and those with upper secondary or post-secondary 
non-tertiary education is at least 6 percentage points. In 12 countries, the difference between adults with upper secondary or post-secondary non-tertiary education and tertiary-educated adults is less than 2 percentage points, implying that upper secondary or post-secondary non-tertiary education is associated with similar outcomes for depression as tertiary education. On average, however, the incidence of selfreported depression falls with each level of educational attainment, from $12 \%$ among adults with below upper secondary education, to $8 \%$ among adults with upper secondary or post-secondary non-tertiary and $6 \%$ among tertiary-educated adults, and this pattern is observed across all countries with data.

Figure 1. Percentage of adults who report having depression, by educational attainment (2014)

European Health Interview Survey and national surveys, 25-64 year-olds

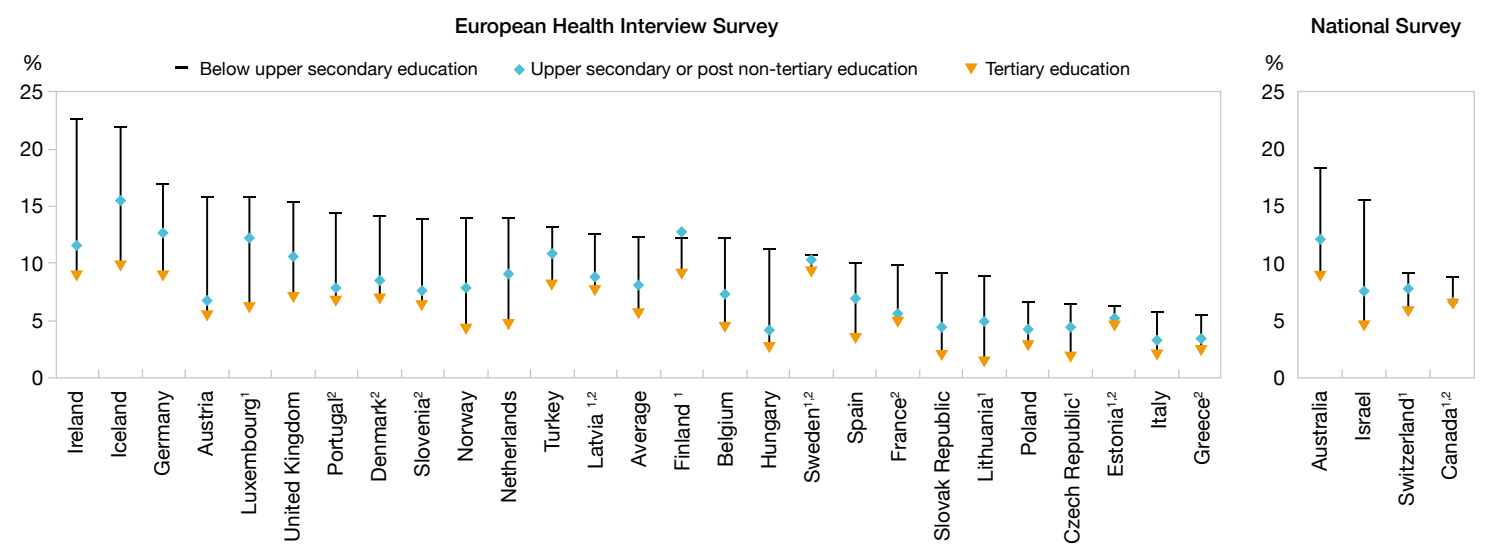

Note: As the questions asked in the different surveys vary, survey results are not directly compared in the analysis.

1. Differences between below upper secondary education and upper secondary or post-secondary non-tertiary education are not statistically significant at $5 \%$.

2. Differences between tertiary education and upper secondary or post-secondary non-tertiary education are not statistically significant at $5 \%$. Countries are ranked in descending order of the percentage of adults with below upper secondary education who report having depression. Source: OECD (2017 $\left.{ }_{[6]}\right)$, Education at a Glance 2017: OECD Indicators, http://dx.doi.org/10.1787/eag-2017-en.

\section{Increasing domestic violence during lockdowns could have long-term implications for educational outcomes}

During confinement, families and couples are forced to spend more time together than ever, creating conditions in which domestic abuse and domestic violence can intensify. Many countries have observed a surge in abuse and dedicated helplines reported large increases of calls in the weeks following the lockdown (The Guardian, 2020 $\left.{ }_{[6]}\right)$.

Research shows that low-educated and unemployed adults are over-represented among the victims of domestic violence, while rates of abuse are significantly lower among highly educated adults (Farmer and Tiefenthaler, $2003_{[7]}$; Lloyd, 1997 ${ }_{[8]}$ ). For perpetrators, the opportunity costs of committing a crime increase with additional years of education, as individuals have better labour market prospects and wages. This partly explains why individuals who display violent behaviour are also more likely to be less educated (Lochner, 2004 $\left[{ }_{[9]}\right.$; OECD, 2017 ${ }_{[10]}$ ). It should be noted, however, that domestic violence also takes place within highly educated households, and the lockdown is likely to increase its prevalence among all families, regardless of their socio-economic status.

Domestic violence is also more prevalent in families with young children and exposure to domestic violence has been found to be detrimental to children's self-esteem, impairing their educational attainment and leaving them more likely to have difficulty forming relationships (Byrne and Taylor, 2007 ${ }_{[11]}$ ). Victims of domestic violence do not only suffer from physical injuries; their situation also affects their social, economic, psychological, spiritual and emotional well-being, and can eventually lead to depression and suicide (Kaur and Garg, 2008 ${ }_{[12]}$ ). Reducing domestic violence inevitably increases feelings of personal safety which in turn contribute to improved mental health; investing in inclusive high-quality education can contribute towards achieving this goal (OECD, 2017 ${ }_{[10]}$ ). 


\section{Tertiary-educated adults are more likely to be in contact with friends and family, even remotely}

The World Health Organization has recommended that during the confinement period, people should eat sufficient and healthy food, engage in physical activity, and stay in contact with family and friends $\left(\mathrm{WHO}, 202 \mathrm{O}_{[33}\right)$. Keeping in touch with friends and family is a practice that increases with educational attainment (OECD, 2019 ${ }_{[13]}$ ), and today, with digital tools, people can maintain a visual contact with friends and family even when confined. Highly educated adults tend to be more socially active and their good information and communications technology (ICT) skills may help them to take advantage of all the possibilities of Internet-based social connections (OECD, 2019 ${ }_{[133}$ ). Data from the Programme for International Student Assessment (PISA) also found significant inequalities in access to technology. For example, virtually every 15-year-old in socio-economically advantaged schools in the United States had a computer to work with at home, but this fell to only three-quarters of students in disadvantaged schools (Reimers and Schleicher, 2020 ${ }_{[14]}$ ).

Figure 2 shows that, in most OECD countries, adults without an upper secondary education are less likely to participate in social media on a daily basis than adults with higher levels of education. The gap between adults with below upper secondary education and tertiary-educated adults is at least 25 percentage points in Greece, Hungary, Portugal and the Slovak Republic. As older adults have lower ICT skills, the gap in Greece and Portugal might be partly explained by the difference in the distribution of educational attainment across age groups. In these two countries, a large share of older adults do not have upper secondary education while the share among younger adults is much lower.

Inequalities in social connections may significantly vary across OECD countries, and physical isolation due to COVID-19 may be easier in countries where Internet-based social connections are common practice. For example, about $50 \%$ of adults in Norway actively participate in social media on a daily basis, regardless of educational attainment, while in France less than 20\% do so (Figure 2).

Figure 2. Internet-based social connections, by educational attainment (2015 or 2017)

$$
\text { 25-64 year-olds }
$$

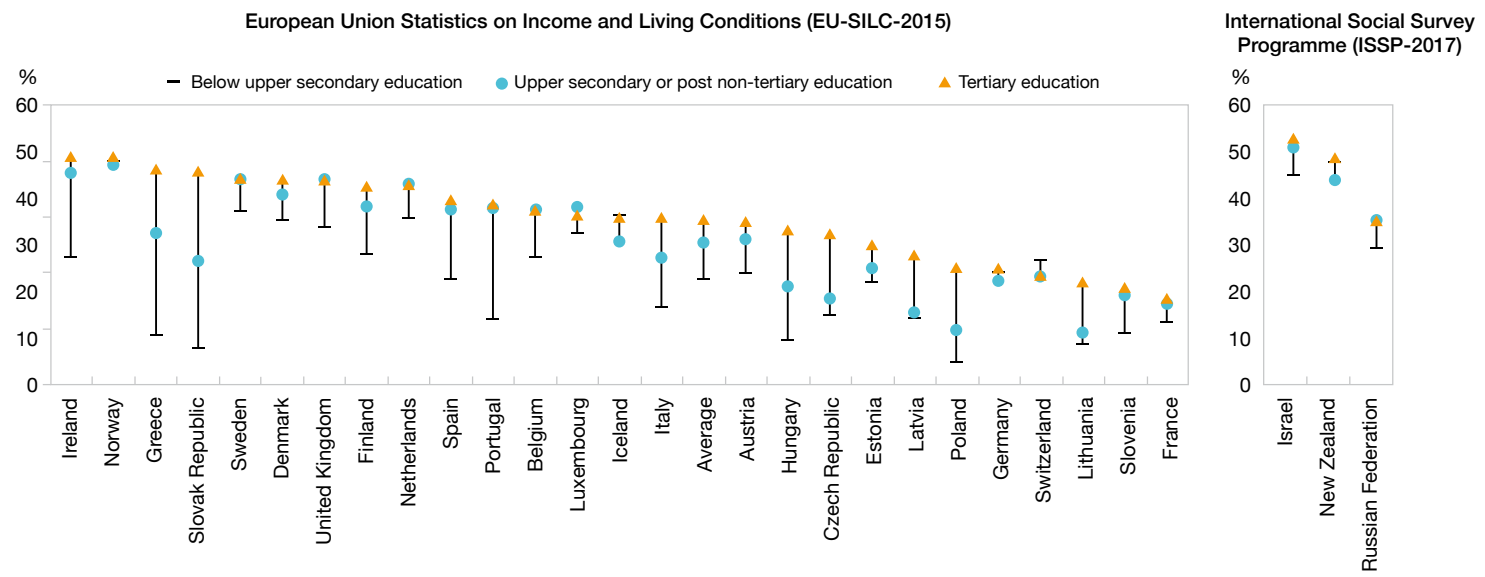

Note: EU-SILC: Adults who actively participate in social media on a daily basis, ISSP-2017: Adults who mostly have contact with their family members and close friends through text messages, mobile phones or other Internet-based communication devices.

Source: OECD (2019 $\left.{ }_{[13]}\right)$, Education at a Glance 2019: OECD Indicators, https://dx.doi.org/10.1787/f8d7880d-en. 
Outside of friends and family, work is a key environment for fostering and maintaining social connections. During confinement, governments are increasingly encouraging workers to rely on teleworking. Teleworking enables the maintenance of some level of economic activity while respecting social distancing. For those who have to change their working habits and make a greater use of computers, access and use of technology can represent a challenge. In all the countries participating in the Survey of Adult Skills (PIAAC), there are many adults with no experience using computers or with extremely limited problem-solving skills in technology-rich environments. On average, around one in four adults have no or only limited experience with computers or lack confidence in their ability to use computers and only half of them were able to conduct basic tasks such as sorting e-mails into pre-existing folders $\left(\right.$ OECD, 2019 $\left.{ }_{[15]}\right)$. Adults with the lowest levels of educational attainment are also those with the lowest proficiency in problem solving in technology-rich environments, implying that equal participation in a world relying strongly on ICT skills can not be taken for granted (OECD, 2015 $[16]$ ).

Adults with low educational attainment can also be disadvantaged because of their profession, either because the nature of their job is considered essential and exposes them to the virus (e.g. cashier, delivery services, taxi driver), or because they unable to execute their profession from home (e.g. hairdresser, construction worker, sales representative). In contrast, tertiary-educated adults are more likely to have jobs they can perform remotely (e.g. professor, government agent, researcher) and be able to earn their full income.

\section{The bottom line}

While the economic benefits of education have been demonstrated in a number of areas, greater educational attainment is also positively associated with a variety of social outcomes that are important during the COVID-19 outbreak. Data collected before the outbreak show that people with a tertiary degree are less likely to report suffering from depression and they are more likely to be in contact with their friends and family physically and through the Internet. During the confinement period, the positive social outcomes of education are more important than ever in equipping individuals to face the crisis. Good mental health, a strong social network and a healthy lifestyle are all associated with the choices individuals made prior to COVID-19, and their choice of whether to continue with their education or not will have been amongst the most important.

\section{REFERENCES :}

[11] Byrne, D. and B. Taylor (2007), "Children at risk from domestic violence and their educational attainment: Perspectives of education welfare officers, social workers and teachers", Child Care in Practice, Vol. 13/3, pp. 185-201, http://dx.doi.org/10.1080/13575270701353465.

[4] Centers for Disease Control and Prevention (2020), Coronavirus Disease 2019 (COVID-19): Daily Life \& Coping: Stress and Coping, https://www.cdc.gov/coronavirus/2019-ncov/daily-life-coping/ managing-stress-anxiety.html (accessed on 08 April 2020).

[7] Farmer, A. and J. Tiefenthaler (2003), "Explaining the recent decline in domestic violence", Contemporary Economic Policy, Vol. 21/2, pp. 158-172, http://dx.doi.org/10.1093/cep/byg002.

[1] Johns Hopkins University (2020), Coronavirus COVID-19 Global Cases by the Center for Systems Science and Engineering (CSSE), https://coronavirus.jhu.edu/map.html (accessed on 16 April 2020).

[12] Kaur, R. and S. Garg (2008), "Addressing domestic violence against women: An unfinished agenda", Indian Journal of Community Medicine, Vol. 33/2, pp. 73-76, http://dx.doi.org/10.4103/0970$\underline{0218.40871 .}$ 
[8] Lloyd, S. (1997), "The effects of domestic violence on women's employment”, Law \& Policy, Vol. 19/2, pp. 139-167, http://dx.doi.org/10.1111/1467-9930.00025.

[9] Lochner, L. (2004), "Education, work, and crime: A human capital approach", NBER Working Paper, No. 10478, National Bureau of Economic Research, Cambridge, MA, http://dx.doi.org/10.3386/ W10478.

[16] OECD (2015), Education at a Glance 2015: OECD Indicators, OECD Publishing, Paris, https://dx.doi. org/10.1787/eag-2015-en.

[10] OECD (2017), Education at a Glance 2017: OECD Indicators, OECD Publishing, Paris, https://dx.doi. org/10.1787/eag-2017-en.

[13] OECD (2019), Education at a Glance 2019: OECD Indicators, OECD Publishing, Paris, https://dx.doi. org/10.1787/f8d7880d-en.

[13] OECD (2019), Education at a Glance 2019: OECD Indicators, OECD Publishing, Paris, https://dx.doi. org/10.1787/f8d7880d-en.

[15] OECD (2019), Skills Matter: Additional Results from the Survey of Adult Skills, OECD Skills Studies, OECD Publishing, Paris, https://dx.doi.org/10.1787/1f029d8f-en.

[2] OECD (2020), Tackling Coronavirus (COVID 19): Contributing to a Global Effort, OECD website, http:// www.oecd.org/coronavirus/en/ (accessed on 21 April 2020).

[14] Reimers, F. and A. Schleicher (2020), "A framework to guide an education response to the COVID-19 Pandemic of 2020", OECD, https://read.oecd-ilibrary.org/view/?ref=126 126988t63lxosohs\&title=A-framework-to-guide-an-education-response-to-the-Covid-19-Pandemicof-2020.

[6] The Guardian (2020), "Lockdowns around the world bring rise in domestic violence", The Guardian, https://www.theguardian.com/society/2020/mar/28/lockdowns-world-rise-domestic-violence (accessed on 20 April 2020).

[5] WHO (2020), Depression fact sheet, World Health Organization website, https://www.who.int/en/ news-room/fact-sheets/detail/depression (accessed on 08 April 2020).

[3] WHO (2020), "Mental health and psychosocial considerations during the COVID-19 outbreak", World Health Organization, https://www.who.int/docs/default-source/coronaviruse/mentalhealth-considerations.pdf (accessed on 30 March 2020).

Photo credit: @ Christopher Futcher / iStock; @ Marc Romanelli / Gettyimages; @ michaeljung / Shutterstock; @ Pressmaster / Shutterstock This work is published under the responsibility of the Secretary-General of the OECD. The opinions expressed and arguments employed herein do not necessarily reflect the official views of OECD member countries.

This document, as well as any data and any map included herein, are without prejudice to the status of or sovereignty over any territory, to the delimitation of international frontiers and boundaries and to the name of any territory, city or area.

The statistical data for Israel are supplied by and are under the responsibility of the relevant Israeli authorities. The use of such data by the OECD is without prejudice to the status of the Golan Heights, East Jerusalem and Israeli settlements in the West Bank under the terms of international law. 